that makes the subjects very fuzzy. The goat moth caterpillar shown in Pl. 6, Fig. 1, looks moribund, but porhaps it is just getting ready to pupate. The black-and-white photographs are of uniform excellence and make one feel that there is a need to discriminate a little bit in the choice of subjects best suited to colour or to black-and-white photography and reproduction when information is to be conveyed by eye to the reader. Some of the colour figures of small caterpillars tell one very littlo indeed.

There is no point in combing the text for trivial errata; but one cannot help wondering how the author, or the editors, at least two of whom are well versed in general taxonomic theory, allowed the family Lasiocampidae (the eggars) to stray out of the super-family Lasiocampoidea into the next super-family Bombycoidea, though they might be forgiven for not realizing that the Endromididae (sic pro Endromidae) of the super-family Bombycoidea were out of place in the super-family Lasiocampoidea (p. 237).

JoHN SMarT

'Kloet. G. S., and Hincks, W. D., "A Check-list of British Insects" (Stockport, 1945).

"Meyrick, E., "A Revised Handbook of British Lepidoptera" (Watkins and Doncaster, London, 1927).

"South, R., "The Moths of the British Isles", 2 vols., revised by

II. M. Edelston (Warne, London, 1939).

\section{AN INTRODUCTION TO PRECAST CONCRETE}

\section{Precast Concrete}

By Dr. Kurt Billig. Pp. xvi +341 . (London: Macmillan and Co., Ltd., 1955.) 32s. net.

T $\mathrm{HE}$ art of precasting concrete has given rise to an ostablished industry producing staple things like blocks, tiles, floor beams and parts for small structures, where problems are in the nature of factory production-engineering, and a more nebulous practice involving the more sophisticated extension of the art to large structures, bridge girders, and so on, which demand the designer's closest attention if the choice of the medium is to be economically justifiable. The whole industry has been profoundly affected within the past decade by the technique of prestressing, which has developed into a competitor with struetural steel.

To deal with the whole subject in a comprehensive manner would domand a writing of considerable dimensions. Dr. Kurt Billig has mentioned most aspects of precast concrete : those forming the basis of organized industry are treated summarily, and attention is given chiefly to the structural uses of reinforced and prestressed precast concrete. In attempting to cover so large a field in a book of about three hundred pages, it is not surprising to find that frequently the treatment is hurried. The aim appears to be the stimulation of interest in the potentialities of structural precast concrete, rather than to present a text-book for the factory engineer or designer. Some 40 per cent of the material has appeared elsewhere; almost the whole of Dr. Billig's earlier work, "Structural Precast Reinforced Concrete", published by the Cement and Concrete Association in 1947, has been reproduced with scarcely any alteration, except that the sections have been re-shuffled to suit the larger work. Dr. Billig has also drawn on his book, "Prestressed Concrete".

The book is divided into four parts: Part 1 deals with design and production; Part 2 with the precast units themselves; Part 3 with joints; and Part 4 with structures in which precast concrete has been used. One might expect difficulties in avoiding overlapping with this breakdown of the subject, but on the whole Dr. Billig handles his matter satisfactorily. There are some cases of repetition, however, and occasionally the meaning becomes elusive, as, for example, "The work done during prestressing levels the discrepancy between the absolute values of the compressive and tensile resistances of the concrete and between the ultimate strains in tension of the steel and the concrete". One or two points seem to recoive disproportionate attention: a discussion on 'æstheties' labours the old problem whether concrete, which looks like stone, can rightly be placed in a position of tension, and six systems are described which use concrete spread on hessian or jute fabric.

References are quoted at the ends of a number of chapters, but Dr. Billig has chosen not to annotate the text in any way to indicate what he may have drawn from these works. This is unfortunate since, for many readers, it defeats the object of such references.

Dr. Billig is at his best when writing about industrial structures, and one wishes that he had gone into greater detail and given more examples. Many of the examples invite the comparison of precast reinforced concrete with in situ concrete. In his chapter on "Efficiency", Dr. Billig has attempted to indicate that the assessment of prestressed concrete should be by comparison with structurel steel. 'That there is a place for both normally reinforced and prestressed precast concrete in the scheme of things seems to have been demonstrated, but what is best done by one or the other does not emerge at all clearly.

T. WHITAKER

\section{ZOOLOGICAL LITERATURE OF 1952}

The Zoological Record

Vol. 89 (Being the Records of Zoological Literature relating chiefly to the year 1952). Edited by G. Burder Stratton. Pp. vi +1450 . (London: Zoological Society of Juondon, 1955.) 120s.

7 OOLOGISTS throughout the world owe a special debt of gratitude to the Zoological Society of London for continuing to produce each year the "Zoological Record". Its compilation is a very heavy task and the general editor, Mr. G. Burder Stratton, and the sectional editors and recorders, in preparing the lists of titles of all zoological publications appearing during the particular year under consideration, have to scarch through hundreds of scientific periodicals in all languages. In addition, the material is classified so as to be of use not only to taxonomists, but also to those engaged in any of the many specialist branches of the subject, such as structure (including histology and cytology), physiology, evolution and genetics, development, reproduction and sex, ecology and habits, geographical distribution, and palæontology and geological distribution. The amount of time saved by having this information thus summarized by specialists in the subjects can only be fully realized by those who have tried to search through the literature on any particular group of animals, or species, previous to 1864 when the "Zoological Record" was founded. 